\title{
Prevalence of thyroid dysfunctions in pregnant women: a prospective study in a tertiary care hospital in Maharashtra, India
}

\author{
Vaishali R. Korde*, Sharin P. Barse, Jaya S. Barla
}

Department of Obstetrics and Gynecology, MIMER Medical College, Dabhade, Pune, Maharashtra, India

Received: 25 May 2018

Accepted: 28 June 2018

\section{*Correspondence:}

Dr. Vaishali R. Korde,

E-mail: vaishali2309@hotmail.com

Copyright: (C) the author(s), publisher and licensee Medip Academy. This is an open-access article distributed under the terms of the Creative Commons Attribution Non-Commercial License, which permits unrestricted non-commercial use, distribution, and reproduction in any medium, provided the original work is properly cited.

\begin{abstract}
Background: Thyroid dysfunction is known to be the commonest endocrinological disorder in pregnancy. A range of adverse outcomes in pregnant women and the fetus have been reported. These can be prevented if the thyroid dysfunction is diagnosed and treated as early as possible. There are limited studies conducted on the prevalence of thyroid dysfunction in pregnancy in India. Hence, this study was conducted for assessment of the prevalence of thyroid dysfunction in pregnancy.

Methods: The present study is a prospective study conducted in the Department of Obstetrics and Gynecology, MIMER Medical College and Hospital, Talegaon, Dabhade, Maharashtra. The total sample population comprised of 705 pregnant women with uncomplicated singleton intra-uterine pregnancy. All participants were screened by estimation for serum TSH in first trimester.

Results: The prevalence of thyroid dysfunction in the present study is $13.9 \%$. Of this, prevalence of hypothyroidism is $12.76 \%$ and that of hyperthyroidism is $1.13 \%$.

Conclusions: With this study, we conclude that there is high prevalence of thyroid dysfunction in pregnancy even in rural population. Thus, a universal screening helps in early diagnosis and preventing the aftermaths of thyroid dysfunction in pregnancy.
\end{abstract}

Keywords: Congenital hypothyroidism, Screening test, Serum TSH, Thyroid disorders in pregnancy

\section{INTRODUCTION}

Thyroid physiology has a very important role in our normal well-being and even more so in pregnancy. Thyroid disorders in pregnancy are usually underestimated in preference to other disorders like anaemia and toxaemia. However, if overlooked, it can have a detrimental effect on the mother as well as the fetus. ${ }^{1}$ The association between overt as well as subclinical thyroid disorders and dysfunction with adverse reproductive outcome is now well understood. ${ }^{2}$

During pregnancy, thyroid glands bear an extra burden, which can result in hypothyroidism. ${ }^{3}$ Even though the dysfunction is associated with serious maternal and fetal morbidities, they are often overlooked because of nonspecific symptoms and hyper metabolic state of pregnancy. There is also alteration in the normal physiology of thyroid during pregnancy. Total $\mathrm{T}_{3}$ and $\mathrm{T}_{4}$ levels increase by $50 \%$ during pregnancy owing to a $50 \%$ increase in thyroxine-binding globulin levels. Serum TSH levels decrease in the first trimester and increase in the second and third trimesters. ${ }^{2,3}$

There is wide geographical variation in the types of thyroid disorders. The prevalence of hypothyroidism in pregnancy is around $2.5 \%$ according to the Western literature. ${ }^{3}$ The prevalence of Grave's Disease is around 
$0.1-0.4 \%$ and that of thyroid autoimmunity is around 5$10 \% .^{3}$ It is found to be more prevalent in the Asian countries as compared to West. ${ }^{4}$ Recent guidelines by American Thyroid Association (ATA) and the National Association of Clinical Biochemists have laid down the cut-off of Serum TSH to $2.5 \mathrm{~m} \mathrm{IU} / \mathrm{L}$ in $1^{\text {st }}$ trimester and $3.0 \mathrm{~m} \mathrm{IU} / \mathrm{L}$ in $2^{\text {nd }}$ and $3^{\text {rd }}$ trimesters. This led to an almost 5 -fold increase in the disease frequency of hypothyroidism in pregnancy. ${ }^{5}$

\section{Hypothyroidism}

Subclinical hypothyroidism ( $\mathrm{SCH})$ is defined an elevated serum TSH level with normal serum thyroxine level and overt/clinical hypothyroidism is defined as high serum TSH with low serum thyroxine levels.

Hypothyroidism is characterized by fatigue, constipation, cold intolerance, muscle cramps and excessive weight gain. A pathologically enlarged thyroid gland depends on the etiology of hypothyroidism and is more likely in women in areas of iodine deficiency or those with hashimoto thyroiditis. Other findings include oedema, dry skin, hair loss and prolonged relaxation phase of deep tendon reflexes.

The most common cause of hypothyroidism in pregnancy is Hashimoto thyroiditis which is characterized by glandular destruction from autoimmune antibodies, particularly anti-thyroid peroxidase antibodies. Clinical identification is difficult as many of the signs and symptoms are common to pregnancy itself.

Hypothyroidism in pregnancy is associated with complications of spontaneous / threatened abortion, preeclampsia, preterm delivery, low birth weight, intrauterine growth retardation and high perinatal mortality. Neonatal hyperbillirubinemia and hypo-/hyperthyroidism are reported too. ${ }^{3}$ These children may also develop attention deficit disorder and hyperactivity syndrome. ${ }^{4}$

\section{Hyperthyroidism}

Subclinical hyperthyroidism is defined as low serum TSH level with normal serum thyroxine level and Overt hyperthyroidism is defined as low serum TSH level with elevated serum thyroxine level. Hyperthyroidism is characterized by tachycardia that exceeds of what is seen in normal pregnancy, failure to gain weight despite of adequate food intake, exophthalmos, thyromegaly, anxiety, palpitations, heat intolerance, warm and wet skin, hand tremors and systolic murmur.

The most common cause of hyperthyroidism in pregnancy is Grave's disease, an organ specific autoimmune process, associated with thyroid stimulating TSH receptor antibodies. Subclinical hyperthyroidism is not associated with adverse outcomes. But if left untreated, it may progress to overt hyperthyroidism and result in complications like pre-eclampsia, preterm labour, low birth weight, fetal and perinatal loss. ${ }^{6}$

\section{Thyroid storm and heart failure}

Both these conditions are acute and life-threatening in pregnancy. Thyroid storm is a hyper-metabolic state and is rare in pregnancy. On the other hand, pulmonary hypertension and heart failure from cardiomyopathy caused by the profound myocardial effects of thyroxin is common in pregnant women. In these women, cardiomyopathy is characterised by high output state which may lead to dilated cardiomyopathy. The pregnant women with uncontrolled thyrotoxicosis have minimal cardiac reserve and the cardiac decompensation is usually precipitated by pre-eclampsia, anemia, sepsis. Frequently thyroxine-induced cardiomyopathy and pulmonary hypertension are reversible

\section{METHODS}

This prospective study was conducted in the Department of Obstetrics and Gynecology, MIMER Medical College and BST Rural Hospital. All antenatal women with uncomplicated intra-uterine pregnancies attending the OPD and IPD in our hospital were included in the study. On enrolment of the patients, a detailed history was taken, and complete examination was done. Selected patients for study were tested for Serum TSH. If it was deranged, then free T3 and free T4 levels was estimated. Patients were treated accordingly and followed up till delivery.

Reference ranges of thyroid hormone levels are (ACOG guidelines 2015):

- $\quad$ Normal TSH levels

a) First trimester: 0.1-2.5 micro IU/ml

b) Second trimester: $0.2-3.0 \mathrm{micro} \mathrm{IU} / \mathrm{ml}$

c) Third trimester: $0.3-3.0 \mathrm{micro} \mathrm{IU} / \mathrm{ml}$

- $\quad$ Normal T3 (T3): 60-200 ng/dl

- $\quad$ Normal T4 (T4): 4.5-12 microgm/dl

All healthy antenatal women with singleton pregnancies and no medical disorder were included in this study. Women with multiple pregnancies, known thyroid abnormalities, known metabolic disorders like diabetes, hypertension and abnormal pregnancies like vesicular mole were excluded from the study.

\section{RESULTS}

According to the demographic distribution, out of 705 patients, $46 \%$ were primigravidas. Mean maternal age was 23.45. Most of the patients were in the age group of 20 to 25 years comprising, a total of $67.37 \%$.

Approximately $11 \%$ of the patients were aged 30 and above. None of the patients had a family history of any thyroid disorders or goitre. 


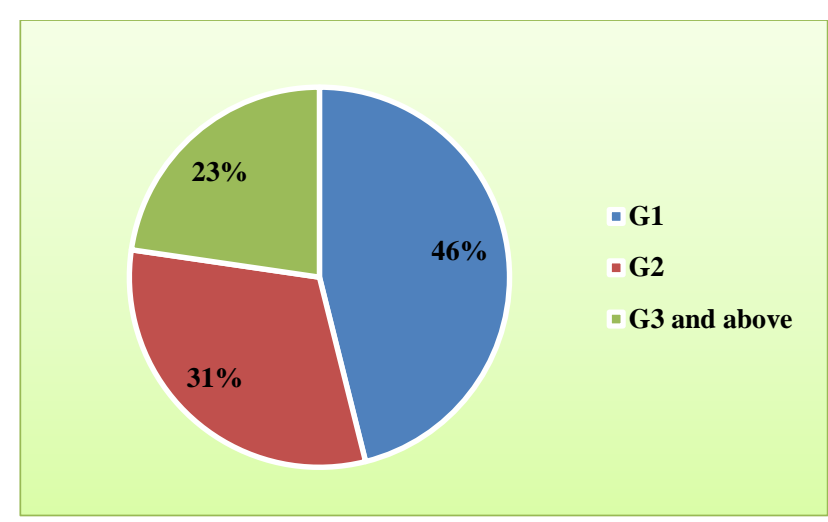

Figure 1: Distribution of cases as per gravidity $(n=705)$.

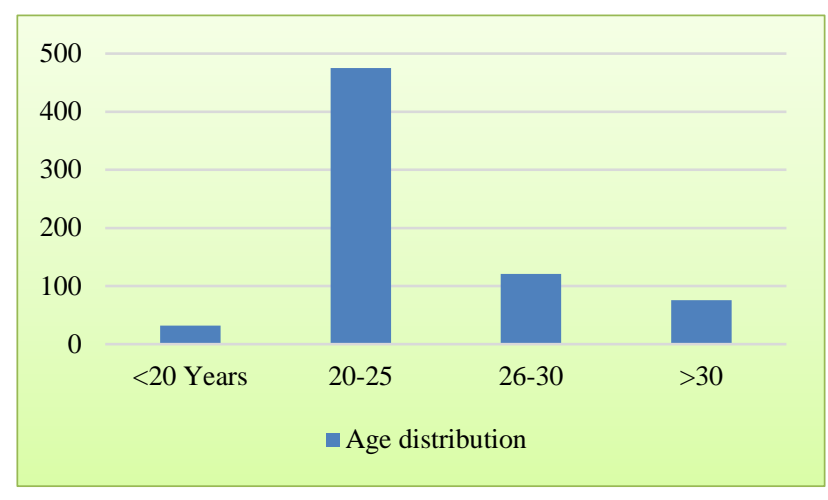

Figure 2: Distribution of cases as per age.

On clinical examination, none of the patients had a goiterous swelling or exophthalmos. On analysing the data, $86 \%$ of the patients were euthyroid. Approximately $14 \%$ had hypothyroidism, out of which $55.6 \%$ had subclinical hypothyroidism and rest had overt hypothyroidism. Out of the total studied population, 8 patients were diagnosed as hyperthyroidism and were started on propylthyrouracil.

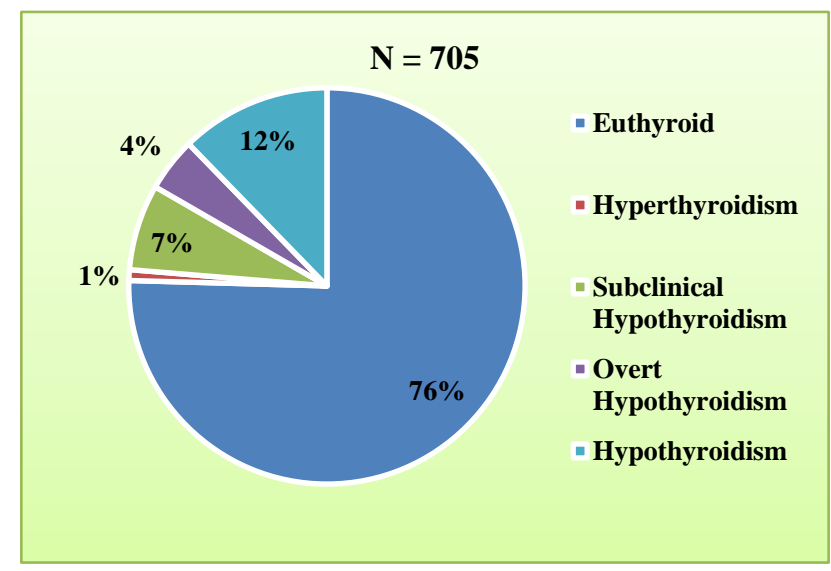

Figure 3: Distribution of as per parameters.

According to present study, most of the primigravida patients had hypothyroidism (46/705), with equal distribution of subclinical (23) and overt (23) disease.
Mean TSH value amongst the studied population was $2.37 \mathrm{mIU} / \mathrm{L}$. The prevalence of thyroid disorders in the present study is $13.9 \%$. Of this, prevalence of hypothyroidism is $13.75 \%$ and that of hyperthyroidism is $0.14 \%$.

\section{DISCUSSION}

In western countries, many studies have shown a lower prevalence of thyroid disorders in pregnancy which is approximately $2.5 \% .^{6-9}$ But Asian studies have shown significant prevalence of thyroid disorders. There are a number of reasons for increased prevalence of hypothyroidism in pregnancy in Asia. For example, diet deficient in iodine, presence of goitrogens in diet, deficiency of micronutrients like selenium and iron. ${ }^{10-12}$

There are few Indian studies regarding the prevalence of thyroid disorders in pregnancy. Sahu et al have done thyroid function in second trimester and reported prevalence of thyroid disorders, especially Overt and Subclinical hypothyroidism to be $6.47 \% .{ }^{13}$ Dhanwal et al conducted a study in 1000 pregnant women in Delhi reporting a prevalence of $14.3 \%$ of hypothyroidism, with a cut off of $4.5 \mathrm{~m} \mathrm{IU/L}$ as upper limit of normal. ${ }^{14}$

A study in Telangana by Nabi VRM et al reported a prevalence of $26 \%$ with a cut off of $3.0 \mathrm{~m}$ IU/L as per ATA guidelines. ${ }^{15}$ In a study conducted by Krishnamma $\mathrm{B}$ et al, the prevalence of thyroid dysfunction was 18.7 with that of hypothyroidism being $13.4 \%$ and of hyperthyroidism $1.3 \%{ }^{16}$

Nambiar $\mathrm{V}$ et al studied the Asian-Indian pregnant women and found the prevalence of hypothyroidism to be $4.8 \% .{ }^{17}$ Dhanwal D et al conducted a multicentric study in 11 cities all over India in 2599 pregnant women and found the prevalence of hypothyroidism to be $13.13 \%$ which is comparable to the present study. ${ }^{18}$

In the present study by Nangia $\mathrm{S}$ et al in two hospitals together in Delhi, a prevalence of thyroid disorders was $1-2 \%$ amongst 400 pregnant women. ${ }^{19}$ Prevalence of hyperthyroidism, both Overt and Subclinical in various studies has been reported to be around $1 \% .{ }^{20}$ In the study conducted by Wang $\mathrm{W}$ et al the prevalence of thyroid disorders was $10.2 \% .^{21}$ Also a study conducted by Taghavi et al reported a prevalence of $14.6 \% .^{22}$

The study conducted by Ajmani et al evaluated 400 pregnant women which concluded a prevalence of $13.25 \% .{ }^{23}$ In the study conducted by Thanuja et al the prevalence of thyroid disorder was less, about $5 \% .{ }^{24}$

In a cross-sectional study conducted by Rajput, et al. which comprised of 461 pregnant women with uncomplicated intrauterine singleton pregnancies in the first trimester of gestation without any history of thyroid disease or intake of any thyroid medication, the prevalence of thyroid disorder was high $(26.5 \%) .^{25}$ 
Due to the significant influence that maternal thyroid dysfunction has on maternal and fetal outcomes, early identification of thyroid dysfunction and timely initiation of treatment is required. Thus, universal screening of pregnant women for thyroid dysfunction should be emphasised, especially in a country like India due to the high prevalence of undiagnosed thyroid dysfunction.

However, an early detection of thyroid dysfunctions and treatment of mother during gestation improves the outcome. Thyroid dysfunction in the mother may also affect the fetus and consequently result in thyroid dysfunction in the fetus as well. Thyroid dysfunction in the neonate is known to hamper not only the mental development but also the somatic growth.

Congenital hypothyroidism is known to result in mental retardation. ${ }^{26}$ In the early days of infancy, the baby may appear normal with no obvious pathological indicators. But Symptoms or signs, when present, may appear in the form of prolonged neonatal jaundice, constipation, lethargy and poor muscle tone, poor feeding, a large tongue, coarse facies, wide fontanelle, distended abdomen and umbilical hernia. ${ }^{27}$ In some studies, the risk of cerebral white matter damage is found to be doubled in neonates with hypothyroidism in the form of echolucencies in infants with low $\mathrm{T} 4{ }^{28}$ It has been observed that infants with T4 levels below threshold develop respiratory distress and need to be supplemented with oxygen for more days, more days on the ventilator and longer hospitalization. ${ }^{29}$

\section{CONCLUSION}

With this study, it is concluded that there is high prevalence of thyroid dysfunction in pregnancy even in rural population. Majority among these being subclinical hypothyroidism. As maternal thyroid dysfunction has significant impact on maternal and fetal outcomes, early identification of thyroid dysfunction and timely initiation of treatment is required. Thus, universal screening of pregnant women in first trimester with $\mathrm{Sr}$. TSH should be emphasised, especially in a country like India due to the high prevalence of undiagnosed thyroid dysfunction. However, an early detection of thyroid dysfunctions and treatment of mother during gestation improves the outcome.

Funding: No funding sources Conflict of interest: None declared

Ethical approval: The study was approved by the Institutional Ethics Committee

\section{REFERENCES}

1. Soldin OP, Tractenberg RE, Hollowell JG, Jonklaas J, Janicic N, Soldin SJ. Trimester-specific changes in maternal thyroid hormone, thyrotropin, and thyroglobulin concentrations during gestation: trends and associations across trimesters in iodine sufficiency. Thyroid. 2004;14:1084-90.

2. de Escobar GM, Obregón MJ, del Rey FE. Maternal thyroid hormones early in pregnancy and fetal brain development. Best Pract Res Clin Endocrinol Metab. 2004;18:225-48.

3. LeBeau SO, Mandel SJ. Thyroid disorders during pregnancy. Endocrinol Metabol Clin North Am. 2006;35(1):117-36.

4. Ghassabian A, Bongers-Schokking JJ, de Rijke YB, van Mil N, Jaddoe VW, de Muinck Keizer-Scharma SM et al. Maternal thyroid autoimmunity during pregnancy and the risk of attention deficit/hyperactivity problems in children. The generation R study. Thyroid. 2012;22:178-86.

5. Stagnaro-Green A, Abalovich M, Alexander E, Azizi F, Mestman J, Negro R et al. Guidelines of the American thyroid association for the diagnosis and management of thyroid disease during pregnancy and postpartum. Thyroid. 2011;21:1081-125.

6. Casey BM, Dashe JS, Wells CE, McIntire DD, Byrd $\mathrm{W}$, Leveno KJ, et al. Sub-clinical hypothyroidism and pregnancy outcomes. Obstet Gynecol. 2005;105:239-45.

7. Glinoer D. The regulation of thyroid function in pregnancy: pathways of endocrine adaptation from physiology to pathology. Endocrine Rev. 1997;18:404-33.

8. Shan ZY. A study for maternal thyroid hormone deficiency during the first half of pregnancy in China. Eu J Clin Invest. 2009;39:37-42.

9. Aoki Y. Serum TSH and total T4 in the United States population and their association with participant characteristics: National Health and Nutrition Examination Survey (NHANES1999-2002). Thyroid. 2007; 17:1211-23.

10. Teng X, Shan Z, Chen Y, Lai Y, Yu J, Shan L, et al. More than adequate iodine intake may increase subclinical hypothyroidism and autoimmune thyroiditis: a cross-sectional study based on two Chinese communities with different iodine intake levels. Eur J Endocrinol. 2011;164:943-50.

11. Marwaha RK, Tandon N, Gupta N, Karak AK, Verma K, Kochupillai N. Residual goitre in the postiodization phase: Iodine status, thiocyanate exposure and autoimmunity. Clin Endocrinol (Oxf). 2003;59:672-81.

12. Das S, Bhansali A, Dutta P, Aggarwal A, Bansal MP, Garg D, et al. Persistence of goiter in the postiodization phase. Micronutrioent deficiency or thyroid autoimmunity? Indian J Med Res. 2011;133:103-9.

13. Sahu MT, Das V, Mittal S, Agarwl A, Sahu M. Overt and subclinical thyroid dysfunction among Indian pregnant women and its effect on maternal and fetal outcome. Arch Gynecol Obstet. 2010;281:215-20.

14. Dhanwal DK, Prasad S, Agarwal AK, Dixit V, Banerjee AK. High prevalence of subclinical hypothyroidism during first trimester of pregnancy in 
North India. Indian $\mathrm{J}$ Endocrinol Metab. 2013;17:281-4.

15. Nabhi VRM, Bhashyakarla U. Prevalence of thyroid dysfunction among pregnant women in a rural teaching. Sch J App Med Sci. 2014;2(6B):2020-5.

16. Krishnamma B. Prevalence of thyroid dysfunction in pregnant women and the need for universal screening: an observational study in Northern Andhra Pradesh population. IJRCOG. 2017;6(6):2536-40.

17. Nambiar V, Jagtap VS, Sarathi V, Lila AR, Kamalanathan S, Bandgar TR, et al. Prevalence and impact of thyroid disorders on maternal outcome in Asian-Indian pregnant women. J Thyroid Res. 2011;2011:429097.

18. Dhanwal DK, Bajaj S, Rajput R, Subramaniam KA, Chowdhury S, Bhandari R, et al. Prevalence of hypothyroidism in pregnancy: An epidemiological study from 11 cities in 9 states of India. Indian $\mathbf{J}$ Endocrinol Metab. 2016;20(3):387-90.

19. Nangia AS, Aggarwal D, Bhatia P, Sharma M, Sarabhai V, Paul M. Prevalence of overt and subclinical thyroid dysfunction among pregnant women and its effect on maternal and fetal outcome. Ind J Obstst Gynecol. 2013;64(2):105-10.

20. Casey BM, Dashe JS, Wells CE, McIntire DD, Leveno KJ, Cunningham FG. Subclinical hyperthyroidism and pregnancy outcomes. Obstet Gynecol. 2006;107:337-41.

21. Wang W. The prevalence of thyroid disorders during early pregnancy in China: The benefits of universal screening in the first trimester of pregnancy. Eu J Endocrinol. 2011;164:263-8.

22. Taghavi M, Saghafi N, Shirin S. Outcome of thyroid dysfunction in pregnancy in Mashhad, Iran. Int J Endocrinol Metab. 2009;2:82-5.
23. Ajmani SN, Aggarwal D, Bhatia P, Sharma M, Sarabhai V, Paul M. Prevalence of overt and subclinical thyroid dysfunction among pregnant women and its effect on maternal and fetal outcome. J Obstet Gynaecol India. 2014;64(2):105-10.

24. Thanuja PM. Thyroid dysfunction in pregnancy and its maternal outcome. J Dental Med Sci. 2014;13(1):11-5.

25. Rajput R. Prevalence of thyroid dysfunction among women during the first trimester of pregnancy at a tertiary care hospital in Haryana. Ind J Endocrinol Metab. 2015;19(3):416-9.

26. Meijer WJ, Verloove-Vanhorick SP, Brand R, van den Brande JL. Transient hypothyroxinaemia associated with developmental delay in very preterm infants. Arch Dis Childhood. 1992;67:944-7.

27. Reuss ML, Paneth N, Pinto-Martin JA, Lorenz JM, Susser M. The relation of transient hypothyroxinemia in preterm infants to neurologic development at two years of age. New Eng J Med. 1996;334:821-7.

28. Leviton A, Paneth N, Reuss ML, Susser M, Allred EN, Dammann O, et al. Hypothyroxinemia of prematurity and the risk of cerebral white matter damage. J Pediatr. 1999:134(6):706-11.

29. Reuss ML, Paneth N, Lorenz JM, Susser M. Correlates of low thyroxine values at newborn screeningg among infants born before 32 weeks gestation. Early Hum Dev. 1997;47(2):223-33.

Cite this article as: Korde VR, Barse SP, Barla JS. Prevalence of thyroid dysfunctions in pregnant women: a prospective study in a tertiary care hospital in Maharashtra, India. Int J Reprod Contracept Obstet Gynecol 2018;7:3211-5. 